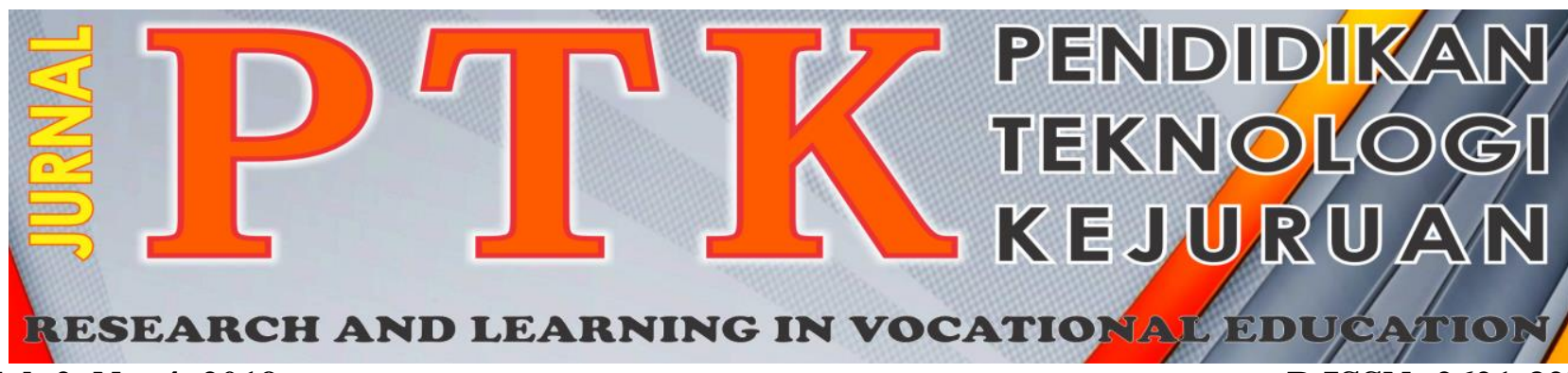

Vol. 2, No. 4, 2019

P-ISSN: 2621-3273

E-ISSN: 2621-1548

\title{
Evaluasi Workshop Penyusunan Proposal Penelitian Tindakan Kelas (PTK) Di Kota Padang Panjang
}

\author{
Donny Fernandez ${ }^{1}$, R. Chandra ${ }^{2}$, Martias ${ }^{3}$ dan Ahmad Arif ${ }^{4}$ \\ 1,2,3,4 Teknik Otomotif, Fakultas Teknik, Universitas Negeri Padang \\ *Corresponding author, e-mail: fernandez_79@yahoo.co.uk ${ }^{1}$
}

\begin{abstract}
Abstrak - Banyak cara dapat digunakan untuk meningkatkan kualitas guru, antara lain melaksanakan Penelitian Tindakan Kelas (PTK). Kualitas pendidikan akan meningkat jika guru memiliki kombinasi kompetensi pedagogic, kepribadian, kompetensi, dan profesional. PTK adalah langkah yang paling tepat untuk meningkatkan kualitas pembelajaran. Peningkatan kualitas ini akan berdampak positif pada guru dan murid. Bagi para guru, PTK adalah tindakan reflektif atas pembelajaran yang dilakukannya. Selama ini, guru masih dianggap kurang mengoptimalkan sumber informasi dalam mengembangkan model pembelajaran yang digunakan. Oleh sebab itu penting bagi seorang guru untuk membuat PTK agar dapat mengetahui kondisi aktual yang dia hadapi. Para peserta lokakarya diberikan pengetahuan tentang aspek-aspek PTK juga dalam persiapan PTK yang baik dan berharap bahwa mereka dapat memberikan penyegaran kepada guru yang berhubungan dengan PTK, sehingga para guru dapat melakukan penelitian serta mampu memecahkan masalah proses pengajaran yang mereka jalani. Selain itu, tujuannya juga untuk merangsang guru untuk menghasilkan artikel tertulis yang diterbitkan di bidang pendidikan. Dalam kegiatan pengabdian masyarakat ini, guru ini dipandu secara langsung sehingga dapat membuat PTK secara mandiri dan juga melalui bimbingan via internet. Dari kegiatan yang dilakukan oleh tim menemukan peningkatan yang sangat signifikan dalam hal pemahaman guru dalam menyiapkan PTK. Ini diperoleh dari pre test yang dilakukan menjelang kegiatan dan post test pasca kegiatan. Meskipun ada peningkatan pemahaman yang signifikan, masih diperlukan inisiatif guru dan dukungan institusi agar guru mampu melahirkan PTK yang lebih baik. Tim pengabdian masyarakat memberikan akses yang luas bagi peserta workshop untuk berdiskusi baik secara lisan maupun melalui jejaring sosial sehingga kompetensi dapat dikembangkan. Selain itu, tim pengabdian kepada masyarakat juga menyediakan modul dan literatur yang dapat digunakan sebagai referensi dalam penyusunan PTK.
\end{abstract}

\section{Kata kunci: Pedagogik, PTK, workshop, literatur}

\begin{abstract}
Many can be used to improve the quality of teachers, among others, the implementation of Classroom Action Research (PTK). Quality of education will increase if teachers have an compose a pediagogic, personality, competence, and professional competency. PTK is the most appropriate step to improve the quality of learning. This quality improvement will positively affect teachers and student. For teachers, PTK is a reflective action over the learning that it does. All this time, the teacher is still considered and assumes his or her other resources out of less effort to improve the model and the learning model used. By performing the PTK, the teacher will know the actual condition that he or she faces. The workshop participants were provided with knowledge about the aspects of PTK also in the preparation of a good PTK and hope that they could provide refreshment to teachers relating to the PTK, so that the teachers could do the research as well as to solve the problem of the teaching process they lead. In addition, the objective is also to stimulate teachers to produce a written article published in the field of education. In the case of the service to the community this teacher is directly guided so as to be able to make the PTK in a separate, multi-disciplinary. From the activities undertaken by the team found a very significant improvement in terms of understanding of teachers in preparing the PTK. This is obtained from the pre test (question and answer) conducted ahead of the activity and post test post activities. Although there is a significant increase in understanding, there is still a need for teachers' independence and intuition in understanding the compilation of PTK more deeply. The community service team provides wide access for workshop participants to communicate both orally and through social networking so that the competence can be developed. In addition, the team devotion to the community also provides modules and literature that can be used as a reference in the preparation of PTK. This experimental research used survey method by distributing questionnaires to respondents with different subject expertise.The results showed that the use of ICTs in learning process has not been implemented optimally. This is caused by the low competence of teachers in the sector of information and communication technology. In addition, the lack of ICT infrastructure in schools causes a deceleration in the development of ICT-based learning models. Comprehensive improvement need to be implemented so that the development of ICT-based learnings model can be performed. The results of this study are expected to provide positive feedback to improve the quality of Indonesian education.
\end{abstract}

Keywords: Pedagogik, PTK, workshop, literature 


\section{Pendahuluan}

Banyak upaya dapat digunakan untuk memperbaiki kualitas pembelajaran, seperti peningkatan mutu sumber daya manusia atau guru, penyediaan sarana-prasarana yang memadai, dan melakukan Penelitian Tindakan Kelas (PTK). Mutu pendidikan akan meningkat jika guru memiliki dan memenuhi [7] kompetensi pedagogik, kompetensi kepribadian, kompetensi sosial, dan kompetensi profesional. UU No. 14 Tahun 2005 tentang Guru dan Dosen menyebutkan bahwa kompetensi adalah seperangkat pengetahuan, keterampilan, dan perilaku yang harus dimiliki, dihayati, dikuasai, dan diaktualisasikan oleh guru dalam melaksanakan tugas keprofesionalan.

Kompetensi pedagogik menjadi kompetensi utama karena menyangkut kemampuan mengelola pembelajaran peserta didik yang meliputi pemahaman terhadap peserta didik, perancangan dan pelaksanaan pembelajaran, evaluasi hasil belajar, dan pengembangan peserta didik untuk mengaktualisasikan berbagai potensi yang dimilikinya. Peraturan Pemerintah RI nomor 74 tahun 2008, tentang Guru, pasal 3 ayat (4) menyebutkan bahwa kompetensi profesional yaitu kemampuan guru dalam penguasaan materi pelajaran secara luas dan mendalam yang memungkinkan membimbing peserta didik memenuhi standar kompetensi yang ditetapkan dalam Standar Nasional Pendidikan. PP Nomor 74 tahun 2008 menjabarkan bahwa kompetensi profesional guru merupakan kemampuan guru dalam menguasai pengetahuan bidang ilmu pengetahuan, teknologi, dan/atau seni dan budaya yang diampunya yang sekurang- kurangnya meliputi penguasaan materi pelajaran secara luas dan mendalam sesuai dengan isi program satuan pendidikan, mata pelajaran, dan/atau kelompok mata pelajaran yang akan diampu serta penguasaan konsep dan metode disiplin keilmuan, teknologi, atau seni yang relevan, yang secara konseptual menaungi atau koheren dengan program satuan pendidikan, mata pelajaran, dan/atau kelompok mata pelajaran yang akan diampu.

Berkenaan dengan itu, Penelitian Tindakan Kelas (PTK) merupakan langkah paling tepat untuk memperbaiki kualitas pembelajaran. Perbaikan kualitas ini akan berpengaruh positif bagi guru dan siswa. Bagi guru, khususnya guru-guru SMK Karya dan SMK Negeri 2 Padang Panjang, PTK merupakan tindakan reflektif atas pembelajaran yang dilakukannya. Selama ini, guru masih dianggap dan menganggap dirinya sebagai satu-satunya sumber belajar sehingga kurang berupaya untuk memerbaiki metode dan model pembelajaran yang digunakan. Dengan melakukan PTK, guru akan mengetahui ${ }^{[6]}$ kondisi riil yang dihadapi anak dan tindakan yang perlu dilakukannya. Jika guru berkenan melakukan PTK, tentu kualitas proses dan hasil pembelajaran pun meningkat. PTK menjadi penting agar murid mendapat prestasi bagus dan guru pun diuntungkan dalam beragam keuntungan. Berdasarkan inspeksi pengusul pada dua sekolah diatas ditemukan masih minimnya kemampuan para guru-guru dalam membuat Penelitian Tindakan Kelas (PTK). Keadaan ini disinyalir karena masih kurangnya penyuluhan yang diterima para guru terkait penyusunan Penelitian Tindakan Kelas (PTK).

\section{METODE}

Untuk mendapatkan hasil yang optimal dari kegiatan pelatihan ini, metode yang digunakan adalah ${ }^{[8]}$ metode ceramah, diskusi, tanya jawab, demontrasi dan praktek langsung, yaitu :

A. Metode ceramah dan tanya jawab

Metode ini digunakan untuk menyajikan teori secara umum. Teori yang disampaikan meliputi konsep dasar penelitian tindakan kelas, langkah-langkah penyusunan rancangan penelitian, langkah-langkah melaksanakan kegiatan penelitian, dan cara melaporkan hasil penelitian. Penyajian materi pada metode ini menggunakan media power point.

B. Metode diskusi

Agar materi yang disampaikan dapat dipahami dengan baik, kepada peserta diberikan modul yang berisikan penjelasan lebih rinci tentang PTK. Semua peserta membaca masing-masing modul yang telah disiapkan, dan kemudian dilanjutkan dengan kegiatan diskusi.

C. Metode praktek

Setelah melakukan presentasi dan diskusi, setiap peserta bekerja untuk menyiapkan sebuah rancangan penelitian PTK yang diharapkan dapat mereka lakukan pada sekolah masing-masing. Adapun materi pelatihan disusun sebagai berikut:

Tabel 1. Materi Pelatihan

\begin{tabular}{|c|l|c|}
\hline & \multicolumn{1}{|c|}{ Materi Workshop } & Jml \\
\hline 1 & Konsep dasar PTK & 5 \\
\hline 2 & $\begin{array}{l}\text { Langkah-langkah penyusunan rancangan } \\
\text { PTK }\end{array}$ & 4 \\
\hline 3 & Prosedur melaksanakan PTK & 4 \\
\hline 4 & Laporan PTK & 3 \\
\hline 5 & Latihan terbimbing via e-mail & 16 \\
\hline & Jumlah jam & 32 \\
\hline
\end{tabular}




\section{HASIL DAN PEMBAHASAN}

Dalam implementasinya kegiatan Pengabdian kepada Masyarakat dapat dibagi menjadi tiga tahapan yaitu: tahapan perencanaan, tahapan pelaksanaan dan evaluasi. Berikut deskripsi masingmasing tahap:

A. Tahapan Perencanaan

Setelah proposal dinyatakan lolos, maka ketua pelaksana mengadakan rapat koordinasi dengan anggota tim. Rapat koordinasi dimaksudkan untuk menyusun rencana kegiatan yang akan diadakan adapun tahapan perencanaan yang dilakukan adalah :

1. Ketua Pelaksana mengundang anggota tim untuk mengadakan rapat koordinasi.

2. Membagi tugas dan tanggung jawab anggota, bentuk tugas yang dibagi tersebut adalah, penyediaan transportasi, koordinasi tempat penginapan, penyediaan Kit, Persiapan Administrasi (blanko daftar hadir peserta, sertifikat dan susunan acara), menyiapkan peralatan administrasi seperti laptop, printer, tinta printer, kertas dan sebagainya.

3. Ketua pelaksana bertugas berkoordinasi dengan kepala sekolah SMK Karya dan SMK Negeri 2 Padang Panjang, guna menginformasikan jadwal kegiatan dan meminta bantuan kepala sekolah untuk menghadirkan peserta.

4. Ketua menghubungi dan memastikan kesediaan pemateri

5. Ketua menginformasikan kepada anggota tentang jadwal keberangkatan ke lokasi.

6. Mendata peserta yang akan mengikuti workshop. Dari perencanaan awal, kegiatan akan diikuti oleh 20 orang guru yang berasal dari SMK Karya dan SMK Negeri 2 Padang.

\section{B. Tahapan pelaksanan}

Pelaksanaan kegiatan diawali dengan persiapan ruangan, kegiatan ini melibatkan 2 orang mahasiswa Jurusan Teknik Otomotif dan 2 orang tenaga kebersihan di SMK Karya Padang Panjang. Di antara persiapan tersebut adalah penyediaan LCD dan layar, jumlah peserta, sound system, snack dan konsumsi dan memastikan bahwa pemateri dapat hadir diwaktu dan tempat yang telah ditentukan. Sebelum dimulainya acara, maka anggota tim ditugasi untuk mengabsensi sekaligus memberikan Kit Seminar kepada peserta. Selanjutnya ketua pelaksana yang didampingi kepala sekolah membuka acara.
Tabel 2. Jadwal Workshop

\begin{tabular}{|c|c|c|c|c|}
\hline No & Materi & Jam & Materi & Pelaksana \\
\hline \multirow{4}{*}{1} & \multirow{4}{*}{$\begin{array}{l}13 \text { Agust } \\
2019\end{array}$} & $08.00-10.00$ & $\begin{array}{l}\text { Berangkat ke } \\
\text { Lokasi }\end{array}$ & Tim Pelaksana \\
\hline & & $10.00-12.00$ & $\begin{array}{l}\text { Pertemuan } \\
\text { denga Kepala } \\
\text { sekolah dan } \\
\text { waka }\end{array}$ & Tim Pelaksana \\
\hline & & $12.00-13.15$ & Isoma & \\
\hline & & $13.15-15.00$ & $\begin{array}{l}\text { Persiapan } \\
\text { ruangan }\end{array}$ & Tim Pelaksana \\
\hline \multirow{7}{*}{2} & \multirow{7}{*}{$\begin{array}{l}14 \text { Agust } \\
2019\end{array}$} & $08.00-08.15$ & $\begin{array}{l}\text { Registrasi } \\
\text { Peserta }\end{array}$ & Tim Pelaksana \\
\hline & & $08.15-09.00$ & Pembukaan & $\begin{array}{l}\text { Ketua Pelaksana } \\
\text { dan Kepsek }\end{array}$ \\
\hline & & $09.00-12.00$ & $\begin{array}{l}\text { Penelitian dan } \\
\text { budaya } \\
\text { penelitian }\end{array}$ & $\begin{array}{l}\text { Dr. R. Chandra, } \\
\text { M.Pd }\end{array}$ \\
\hline & & $12.00-13.00$ & Isoma & Tim Pelaksana \\
\hline & & $13.00-15.30$ & $\begin{array}{l}\text { Konsep dasar } \\
\text { PTK }\end{array}$ & $\begin{array}{l}\text { Drs. Andrizal, } \\
\text { M.Pd }\end{array}$ \\
\hline & & $15.30-16.00$ & Istirahat & \\
\hline & & $16.00-17.00$ & $\begin{array}{l}\text { Desain/Ranca } \\
\text { ngan PTK }\end{array}$ & $\begin{array}{l}\text { Drs. Andrizal, } \\
\text { M.Pd }\end{array}$ \\
\hline \multirow{6}{*}{3} & \multirow{6}{*}{$\begin{array}{l}15 \text { Agust } \\
2019\end{array}$} & 08.30-09.00 & $\begin{array}{l}\text { Absensi } \\
\text { Peserta }\end{array}$ & Tim Pelaksana \\
\hline & & $09.00-11.30$ & $\begin{array}{l}\text { Desain/Ranca } \\
\text { ngan PTK }\end{array}$ & $\begin{array}{l}\text { Drs. Andrizal, } \\
\text { M.Pd }\end{array}$ \\
\hline & & $11.30-13.00$ & Isoma & Tim Pelaksana \\
\hline & & $13.00-15.30$ & $\begin{array}{l}\text { Penyusunan } \\
\text { Proposal } \\
\text { PTK }\end{array}$ & $\begin{array}{l}\text { Drs. Andrizal, } \\
\text { M.Pd, Dr. R. } \\
\text { Chandra, M.Pd., } \\
\text { Toto Sugiarto, } \\
\text { S.Pd.,M.Si., }\end{array}$ \\
\hline & & $15.30-16.00$ & Istirahat & \\
\hline & & $16.00-17.15$ & $\begin{array}{l}\text { Penyusunan } \\
\text { PTK } \\
\text { (Lanjutan) }\end{array}$ & $\begin{array}{l}\text { Drs. Andrizal, } \\
\text { M.Pd, Dr. R. } \\
\text { Chandra, M.Pd., } \\
\text { Toto Sugiarto, } \\
\text { S.Pd.,M.Si., }\end{array}$ \\
\hline \multirow{7}{*}{4} & \multirow{7}{*}{$\begin{array}{l}16 \text { Agust } \\
2019\end{array}$} & 08.30-09.00 & $\begin{array}{l}\text { Absensi } \\
\text { Peserta }\end{array}$ & Tim Pelaksana \\
\hline & & $09.00-11.30$ & $\begin{array}{l}\text { Penyusunan } \\
\text { PTK } \\
\text { (Lanjutan) }\end{array}$ & $\begin{array}{l}\text { Dr. R. Chandra, } \\
\text { M.Pd., Toto } \\
\text { Sugiarto, } \\
\text { S.Pd.,M.Si., Drs. } \\
\text { Martias, M.Pd } \\
\end{array}$ \\
\hline & & $11.30-13.00$ & Isoma & Tim Pelaksana \\
\hline & & $13.00-15.30$ & $\begin{array}{l}\text { Penyusunan } \\
\text { PTK } \\
\text { (Lanjutan) } \\
\end{array}$ & $\begin{array}{l}\text { Toto Sugiarto, } \\
\text { S.Pd.,M.Si., Drs. } \\
\text { Martias, M.Pd }\end{array}$ \\
\hline & & $15.30-16.00$ & Istirahat & \\
\hline & & $16.00-17.00$ & $\begin{array}{l}\text { Penyusunan } \\
\text { PTK } \\
\text { (Lanjutan) } \\
\end{array}$ & $\begin{array}{l}\text { Toto Sugiarto, } \\
\text { S.Pd.,M.Si., Drs. } \\
\text { Martias, M.Pd }\end{array}$ \\
\hline & & 17.00 & $\begin{array}{l}\text { Penutupan } \\
\text { kegiatan }\end{array}$ & $\begin{array}{l}\text { Tim Pelaksana } \\
\text { dan Kepsek }\end{array}$ \\
\hline
\end{tabular}

C. Evaluasi Pelaksanaan Kegiatan

Setelah dilaksanakan workshop Penyusunan Penelitian Tindakan Kelas (PTK) bagi Guru-guru SMK Karya dan SMK Negeri 2 Padang Panjang yang diadakan tanggal 13 sampai dengan 16 Agustus 2019. Evaluasi pada kegiatan ini diantaranya adalah:

1. Berdasarkan evaluasi tentang pengetahuan guru pada hari pertama workshop diadakan dapat disimpulkan sebagian besar guru-guru belum memahami konsep Penelitian Tindakan Kelas (PTK). Kondisi tersebut berubah setelah 
kegiatan workshop dilaksanakan, hal tersebut tidak terlepas dari keingintahuan peserta saat kegiatan berlangsung, hal ini dapat diamati dari antusias guru- guru untuk mengikuti kegiatan. Respon dan antusias guru-guru sangat baik, hal ini ditandai dengan tingkat kehadiran sejak awal kegiatan sampai penutupan serta banyaknya pertanyaan-pertanyaan yang diajukan oleh guru-guru pada narasumber.

2. Dihasilkannya beberapa judul-judul Penelitian Tindakan Kelas (PTK) yang diajukan oleh guruguru kepada narasumber untuk selanjutnya dibahas dan diberi masukan judul-judul yang berkaitan dengan permasalahan yang ditemui guru pada proses belajar mengajar.

\section{KESIMPULAN}

Dari kegiatan pengabdian masyarakat yang dilaksanakan di SMK Karya yang juga diikuti oleh peserta guru-guru dari SMK Negeri 2 Padang Panjang dapat diambil kesimpulan bahwa pembuatan PTK menjadi salah satu persaratan berat bagi para guru sebagai bahan untuk kenaikan pangkat dikarenakan kebiasaan menulis yang rendah. Selanjutnya, permasalahan sulitnya membuat PTK sebetulnya dapat diatasi dengan membentuk grup diskusi dimana setiap peserta saling sharing pengalaman dan informasi terkait. Ini terlihat dari antusiasme dan semangat guru bekerja ketika berada dalam kelompok diskusi.

1. Untuk menghasilkan karya tulis yang baik (PTK) memang dibutuhkan sumber/literatur yang lengkap serta narasumber yang kompeten. Ini seharusnya menjadi perhatian sekolah agar permasalahan lemahnya kemampuan guru dalam menulis dapat diatasi.

2. Adapun saran terkait kegiatan Pengabdian kepada Masyarakat ini yaitu, diharapkan adanya peningkatan intensitas diskusi kelompok dan pertemuan guru-guru dalam menyusun PTK. Selain itu, Pihak sekolah memiliki peran penting dalam menyiapkan SDM di sekolah masingmasing. Sekolah yang sadar akan pentingnya pembangunan SDM maka sekolah itu akan dibangun oleh guru-guru yang berkualitas.

3. Materi yang diperoleh peserta adalah gambaran pembuatan PTK secara umum. Diharapkan untuk peserta agar mengembangkan dan mengimplementasikan ilmu yang diperoleh.

\section{DAftar Pustaka}

[1] Kemmis \& Mc. Taggart. 1994. The Action Research Planner. Geelong: Deaken University Press.
[2] Millis, G.E. 2000. Action Research; A Guide for the Teacher Research. Columbus: Merrill's Am Imprint of Prentice Hill.

[3] Pusat Pembinaan dan Pengembangan Bahasa. 1995. Kamus Besar Bahasa Indonesia (KBBI). Jakarta: Balai Pustaka.

[4] Ristasa, R dan Prayitno. 2006. Panduan Penelitian Tindakan Kelas. Purwokerto: UPBJJ Purwokerto.

[5] Suharsimi Arikunto, dkk. 2009. Penelitian Tind akan Kelas. Jakarta: Bumi Aksara.

[6] Suharsimi Arikunto. 1993. Penelitian Tindakan Kelas (PTK). Jakarta: Departemen Pendidikan dan Kebudayaan.

[7] Tim Pelatih Proyek PGSM. 1999. Penelitian Tindakan Kelas. Jakarta: Departemen Pendidikan dan Kebudayaan.

[8] Hidayat, Nuzul., Arif, Ahmad,. Setiawan, M.Yasep,. Afnison, Wanda., 2018. Peningkatan Pengetahuan dan Keterampilan Pemuda Putus Sekolah Melalui Pelatihan Perawatan Berkala Sepeda Motor. INVOTEK Volume 18 number 2 , 83-89 (2018)

\section{Biodata Penulis}

Donny Fernandez, Lahir di Muara Panas tanggal 18 Januari 1979, Menyelesaikan Sarjana Pendidikan (S.Pd) di Jurusan Teknik Otomotif FT UNP tahun 2003. Pada tahun tersebut mengikuti seleksi penerimaan calon dosen dan diterima sebagai calon Dosen di jurusan yang sama. Tahun 2008 melanjutkan studi ke Universitas Gadjah Mada bidang Ilmu Lingkungan dan tahun 2010 dapat menyelesaikan S2 (M.Sc). Tahun 2013 ditugasi untuk mengikuti Bridging Program ke Kun Shan University di Taiwan. dan sejak tahun 2015 ditugasi sebagai sekretaris Jurusan Teknik Otomotif FT UNP.

R. Chandra, Lahir di Medan tanggal 27 November 1957, menyelesaikan Sarjana Muda di IKIP Bandung, kemudian Melanjutkan Pendidikan Magister (M.Pd) di IKIP Yogyakarta dan selanjutnya menyelesaikan Doktoral (Dr) di IKIP Jakarta. Pernah menjabat sebagai Dekan Fakultas Teknik saat itu masih bernama FPTK IKIP Padang.

Martias, Lahir di Ladang Lawas tanggal 1 Agustus 1964, menyelesaikan program sarjana (Drs) di IKIP Padang, selanjutnya menyelesaikan pendidikan Strata dua di Fakultas Teknik Universitas Negeri Padang (M.Pd). saat ini menjabat sebagai Ketua Jurusan Teknik Otomotif Fakultas Teknik Universitas Negeri Padang 
Ahmad Arif, Merupakan seorang staf pengajar tetap di Jurusan Teknik Otomotif UNP sejak tahun 2015. Memperoleh gelar Sarjana Pendidikan (S.Pd) bidang Teknik otomotif dari UNP pada tahun 2009 dan menyelesaikan Magister Teknik (MT) di Institut Teknologi Sepuluh Nopember Surabaya pada tahun 2015. 